\title{
Metal Nanoparticles Supported on Al-MCM-41 via In Situ Aqueous Synthesis
}

\author{
Ivonne Alonso-Lemus, ${ }^{1}$ Ysmael Verde-Gomez, ${ }^{2}$ Alfredo Aguilar-Elguézabal, ${ }^{1}$ \\ and Lorena Álvarez-Contreras ${ }^{1}$ \\ ${ }^{1}$ Departamento de Química de Materiales, Centro de Investigación en Materiales Avanzados, S.C. Miguel de Cervantes 120,
Complejo Industrial Chihuahua, Chih 31109, Mexico
${ }^{2}$ Instituto Tecnológico de Cancún, Av. Kabah km. 3. Cancún, QR 77500, Mexico
}

Correspondence should be addressed to Lorena Álvarez-Contreras, lorena.alvarez@cimav.edu.mx

Received 29 April 2010; Accepted 19 July 2010

Academic Editor: Shijun Liao

Copyright (C) 2010 Ivonne Alonso-Lemus et al. This is an open access article distributed under the Creative Commons Attribution License, which permits unrestricted use, distribution, and reproduction in any medium, provided the original work is properly cited.

\begin{abstract}
MCM-41 have been used to custom synthesize catalysts in because of the controllable properties, such as pore size, active phase incorporation, crystal size, and morphology, among others. In this paper, a simple and versatile method for the incorporation of platinum, ruthenium, and palladium onto Al-MCM-41 mesoporous silica by direct inclusion of various precursors was studied. M/Al-MCM-41 structure, textural properties, morphology, and elemental composition were analyzed. The results obtained indicate that the Al-MCM-41 mesoporous-ordered structure was not affected by metallic particle incorporation. Highsurface areas were obtained $\left(1131 \mathrm{~m}^{2} / \mathrm{g}\right)$. Metallic nanoparticles dispersion on Al-MCM-41 was homogeneous for all samples and its particles sizes were between $6 \mathrm{~nm}$ to $20 \mathrm{~nm}$. Microscopy results show round shape particles in platinum and palladium samples; however, ruthenium catalysts exhibit a spherical and rod shapes. Electrochemical testing for Pt/Al-MCM-41 showed electrocatalytic activity for $\mathrm{H}_{2}$ oxidation which indicates that these materials can be used as a catalyst in electrochemical devices.
\end{abstract}

\section{Introduction}

Mesoporous materials have played an important role in catalytic applications [1-3]. Despite the availability of natural mesoporous materials, their use is limited in catalytic applications due to the presence of undesired phases. The chemical composition of natural mesoporous materials changes from one mineral deposit to another, even from one stratum to another in the same mine. Unfortunately, this makes it difficult to optimize their properties for tailor applications. Thus, custom synthesizing mesoporous materials by incorporating metallic particles is an important issue for the development of catalytic applications [4].

Kresge et al. discovered a series of mesoporous materials named as the M41S family [5]. The M41S family has three members: MCM-41 with a hexagonal array of unidirectional pores, MCM- 48 with a three-dimensional cubic pore structure, and MCM-50 with an unstable lamellar structure. These materials have exceptionally high-surface areas $\left(>1000 \mathrm{~m}^{2} / \mathrm{g}\right)$ and narrow pore size distributions [6]. Among the three members of the M41S family, MCM41 became the most popular mesoporous molecular sieve. MCM-41 has been used in many applications such as production of intermediates/fine chemicals, petrochemical reactions [7, 8], optical applications [9], development of sensors [10], and different industrial reactions (e.g., oxidation, condensation, and enzymatic reactions) [11-15]. MCM-41 is better option than microporous zeolites for some applications with diffusional problems, especially when large reacting molecules are involved.

Preparation methods to support metals on mesoporous materials are complicated and involve several steps in order to produce nanoparticles. Different synthesis methods have been developed for depositing metallic particles into mesoporous supports. The incipient wetness impregnation method has the advantage of technical simplicity and reproducible metal loading [16-18]. However, metal distribution may be affected upon subsequent drying. Yao et al. [19] 
introduced a technique called vacuum evaporation impregnation to prepare $\mathrm{Pt}$ into MCM-41. Through the use of this impregnation method, it was possible to obtain material with a high specific surface area $\left(900 \mathrm{~m}^{2} / \mathrm{g}\right)$ and $1.26 \%$ wt. of platinum as maximum loading. Junges et al. [20] compared three synthesis methods for preparing Pt/MCM41: (i) direct platinum incorporation during the MCM41 synthesis, (ii) incipient wetness, and (iii) ion exchange. The best performance was achieved over samples prepared by means of incipient wetness method. According to the authors, the nanometric size of the Pt-particles (around $2 \mathrm{~nm}$ ) promoted high conversions in CO oxidation. Other mesoporous materials such as MSU (Michigan State University material) have been evaluated in some catalytic applications. Aramendía et al. [21] supported Pt metallic particles in MSU prepared by direct synthesis. Platinum particle size was $6 \mathrm{~nm}$ and specific surface area between 600 $850 \mathrm{~m}^{2} / \mathrm{g}$.

Often, the incorporation of the active phase is carried out after support synthesis and has been reported in many works [22-29]. A new technique which uses supercritical fluids has been developed for incorporating platinum into FSM-16 $[22,23]$. The use of $\mathrm{CO}_{2}$ in the supercritical state improves active phase dispersion. Yamamoto et al. [24, 25] prepared platinum carbonyl clusters in FSM-16 by a "ship-in-thebottle" technique. The technique consists of encapsulating $\left[\mathrm{Pt}_{3}(\mathrm{CO})_{6}\right]_{5}{ }^{-2}$ clusters in the FSM-16 hexagonal channels. However, a disadvantage of this technique is that the carbonyl groups must be carefully evacuated in order to conserve the mesoporous support structure.

Different metallic particles have been supported in MCM-41 for several catalytic applications. Ruthenium [26] and bimetallic particles such as $\mathrm{Ru}-\mathrm{Pt}$ [27] and $\mathrm{Ru}-\mathrm{Cu}$ [28] have been supported after MCM-41 synthesis. Palladium in MCM-41 has been reported [29] and can be used for polluted groundwater treatment [30] and Heck reactions [31, 32]. In all cases, the objective of catalyst synthesis is to have a homogeneous and high dispersion of the active phase with a very small metallic particle size.

This work presents a simple and versatile synthesis method for metallic nanoparticles (i.e., $\mathrm{Pt}, \mathrm{Ru}$, and $\mathrm{Pd}$ ) supported on mesoporous silica. Al-MCM-41 was used as support because has been demonstrated that $\mathrm{Al}$ can be incorporated in silica lattice substituting a Si atom [33]. With aluminum inclusion is expected to modify the surface acidity of mesoporous support creating anchorage sites for the metallic nanoparticles. The physical, chemical, and electrochemical properties of the synthesized materials are also discussed.

\section{Experimental}

2.1. Metals/Al-MCM41 Synthesis. The metal/Al-MCM-41 (M/Al-MCM-41) materials were prepared as follows: a fixed amount of sodium aluminate $\left(\mathrm{NaAlO}_{2}, 99.95 \%\right.$, Riedel-de Haën) was dissolved in $6 \mathrm{M}$ ammonium hydroxide $\left(\mathrm{NH}_{4} \mathrm{OH}\right.$, $30 \%$, Aldrich) solution (molar ratio of $\mathrm{Si} / \mathrm{Al}=20$ ). Then, each metal precursor was dissolved in this alkaline solution. The solution was combined with cetyl trimethyl ammonium bromide (CTAB, 99\%, Alfa Aesar) as organic template (CTAB/Si molar ratio was 0.12). Finally, the mixture was stirred in order to ensure a clear homogeneous solution; then tetraethyl orthosilicate (TEOS, 98\%, Aldrich) was added as silica source. Solution was stirred for $24 \mathrm{~h}$ at room temperature and atmospheric pressure. Metal precursor was calculated in order to have 5\% wt of metal supported in Al-MCM41. Ammonium hexachloroplatinate $\left(\left(\mathrm{NH}_{4}\right)_{2} \mathrm{PtCl}_{6}, 99.9 \%\right.$, Alfa Aesar), ammonium hexachloropaladate $\left(\left(\mathrm{NH}_{4}\right)_{2} \mathrm{PdCl}_{6}\right.$, 99.9\%, Alfa Aesar), and ruthenium chloride ( $\mathrm{RuCl}_{3}$, Aldrich) were used as metal precursors for $\mathrm{Pt}, \mathrm{Pd}$, and $\mathrm{Ru}$, respectively. In all cases, the resulting synthesized products were recovered by filtration and washed with deionized water. The products were calcined in air at $823 \mathrm{~K}$ during 4 hours. The M/AlMCM-41 materials were reduced in hydrogen atmosphere at $673 \mathrm{~K}$ during 4 hours. Additionally, an Al-MCM-41 sample control was synthesized.

2.2. Physical and Chemical Characterization. X-Ray diffraction (XRD) was used to determine crystalline structure and crystallite size in all samples. An analytical X'PertPRO diffractometer $(\mathrm{CuK} \alpha-1$ radiation $(40 \mathrm{kV}, 30 \mathrm{~mA})$, step size $=$ $0.016^{\circ}, 24.13 \mathrm{~s}$ per step) was used with an X'Celerator accessory at room temperature.

Nitrogen adsorption analyses were performed in order to evaluate textural properties of samples such as surface area, pore size distribution, and pore shape. Nitrogen adsorption isotherms were determined by a Quantachrome Autosorb1 gas sorption analyzer using high-purity nitrogen as adsorbate. Prior to adsorption isotherm determination, the samples were outgassed for $5 \mathrm{~h}$ at $573 \mathrm{~K}$; surface area was obtained by multipoint BET method.

In order to have an approximation of the elemental composition and metal loading in M/Al-MCM-41 samples, energy dispersive spectroscopy (EDS) was carried out with EDAX Prime equipment coupled to a JEOL 5800 LV Scanning Electron Microscope; the analyses were randomly taken in several sample zones to have a representative value of the elemental composition at low magnification. Morphological characterization was carried out using a Philips CM-200 (200 KV, $25 \mathrm{pA})$ transmission electron microscope (TEM) and JEOL7410 (5.0 KV) Field Emission Scanning Electron Microscope (FESEM). TEM and SEM specimens were prepared by dispersing the sample in ethanol with ultrasound for 5 minutes. A drop of the suspension was placed into a holey carbon $\mathrm{Cu}$ grid and was allowed to dry.

2.3. Electrochemical Experiment. Electrochemical characterization was carried out by cyclic voltammetry (CV) in a conventional three-electrode cell. A glassy carbon disk electrode with a surface area of $0.07 \mathrm{~cm}^{2}$ was used as working electrode. Catalyst suspension was prepared with M/Al-MCM-41 and Vulcan XC72 (Cabot Corporation) at a $1: 1$ weight ratio dispersed in deionized water. Catalyst suspension which contained $10 \mathrm{mg} / \mathrm{mL}$ was spread on the disk electrode from the ultrasonicated aliquots. Catalyst film was fixed on the disk electrode using $5 \mu \mathrm{L}$ of a deionized water: Nafion solution (20:1 ratio) and dried at room temperature. Electrochemical measurements were performed 


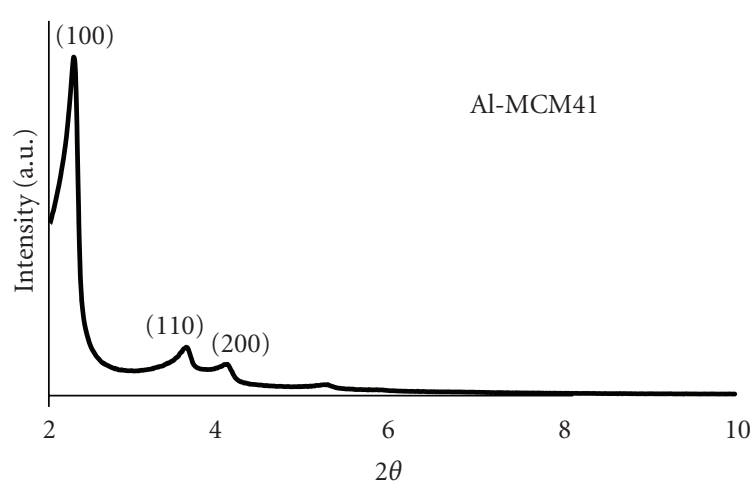

(a)

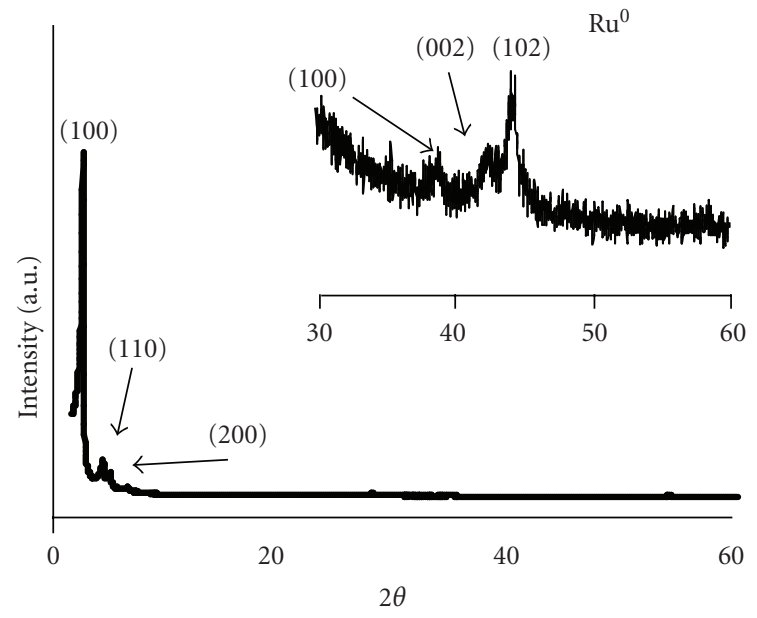

(c)

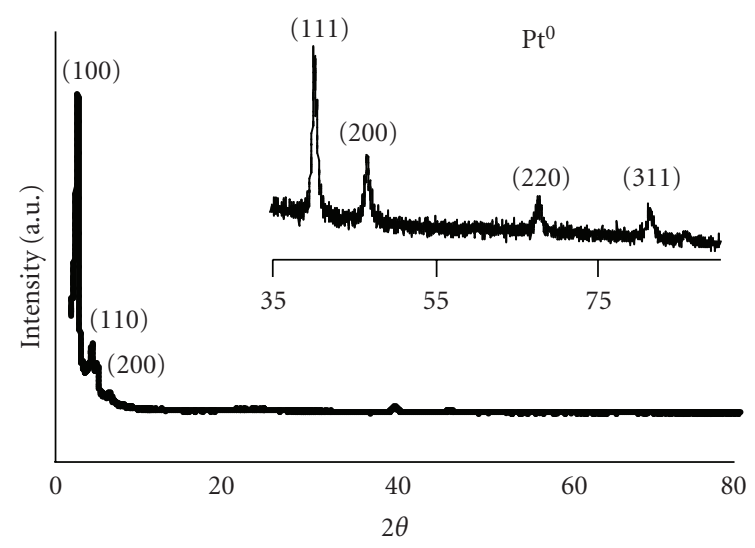

(b)

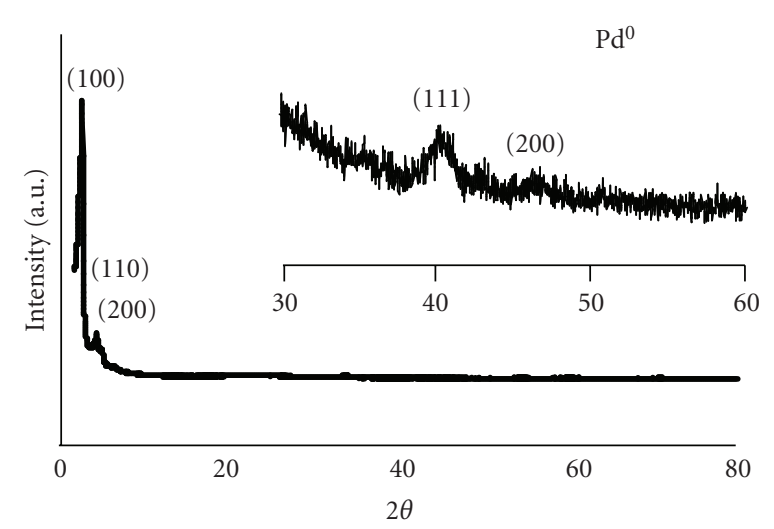

(d)

Figure 1: XRD pattern from (a) Al-MCM-41, (b) Pt/Al-MCM-41, (c) Ru/Al-MCM-41 and (d) Pd/Al-MCM-41.

at $298 \mathrm{~K}$ using a Princeton Applied Research VersaSTAT3 potentiostat/galvanostat. A three-electrode cell was used with a saturated calomel electrode (SCE: $\mathrm{Hg} / \mathrm{Hg}_{2} \mathrm{Cl}_{2} /$ sat. $\mathrm{KCl}$ ) as reference electrode and platinum foil as counter electrode. The CV studies were performed in $0.5 \mathrm{M} \mathrm{H}_{2} \mathrm{SO}_{4}$ electrolyte solution saturated with argon at potential range -0.3 to $0.6 \mathrm{~V}$ versus SCE and scan rate of $20 \mathrm{mVs}^{-1}$. The results were plotted versus Normal Hydrogen Electrode (NHE)

\section{Results and Discussion}

3.1. X-Ray Diffraction. Figure 1 shows the XRD patterns for the M/Al-MCM-41 materials. Typically, MCM-41 silica exhibited three peaks at small angles (Figure 1(a)). These peaks are characteristics of hexagonal ordered structures [34] and correspond to (100), (110), and (200) planes. M/AlMCM-41 mesoporous structure was not affected after metal incorporation and thermal treatment. This suggests that the M/Al-MCM-41 was structurally stable. Table 1 summarizes the chemical and physical properties of M/Al-MCM-41 synthesized.

Interplanar distance can be directly related to MCM-41 pore size due to the fact that unit cell is hexagonal [35].
The (100) peak represents the $d$ spacing. The $d$ spacing obtained from Al-MCM-41 sample was $3.89 \mathrm{~nm}$, while the $d$ spacing of M/Al-MCM-41 materials decreases between 0.1 to $0.3 \mathrm{~nm}$ respect to pure Al-MCM-41 (Pt/Al-MCM41 $\sim 3.55 \mathrm{~nm}, \mathrm{Pd} / \mathrm{Al}-\mathrm{MCM} 41 \sim 3.62 \mathrm{~nm}$, and Ru/Al-MCM41 $\sim 3.73 \mathrm{~nm}$ ). Interplanar distance modification observed in M/Al-MCM-41 samples suggests a possible introduction of $\mathrm{Pt}, \mathrm{Pd}$ and $\mathrm{Ru}$ into to the silica network.

Additionally, peaks at high angles were observed indicating the presence of metallic crystalline phases. The peaks were indexed as platinum, ruthenium, and palladium in metallic state (Figures 1(b), 1(c) and 1(d), resp.).

Crystal sizes for metallic particles supported in Al-MCM41 were calculated from the Scherrer equation

$$
L=\frac{0.9 \lambda}{\beta \cos \theta},
$$

where $L$ is the crystallite size $(\AA), \lambda$ the wavelength $(\AA)$, $\beta$ is the line broadening at half the maximum intensity in radians and the $\theta$ the angle of the highest peak in radians. The crystallites sizes calculated from Scherrer equation are shown in Table 1. Pt/MCM-41 and Pd/MCM41 crystallites sizes ( $8 \mathrm{~nm}$ and $6 \mathrm{~nm}$, resp.) were smaller than the Ru/MCM-41 
TABLE 1: Chemical and physical properties of M/Al-MCM-41 materials.

\begin{tabular}{lcccc}
\hline Sample & Metal crystallite size, XRD $(\mathrm{nm})$ & $S_{\text {BET }}\left(\mathrm{m}^{2} / \mathrm{g}\right)$ & BJH pore size $(\mathrm{nm})$ & Metal loading \%wt. \\
\hline Al-MCM-41 & - & 1272 & 2.5 & - \\
Ru/Al-MCM-41 & 14 & 998 & 2.6 & 3.14 \\
Pd/Al-MCM-41 & 6 & 879 & 2.5 & 3.40 \\
Pt/Al-MCM-41 & 8 & 1131 & 2.7 & 4.28 \\
\hline
\end{tabular}

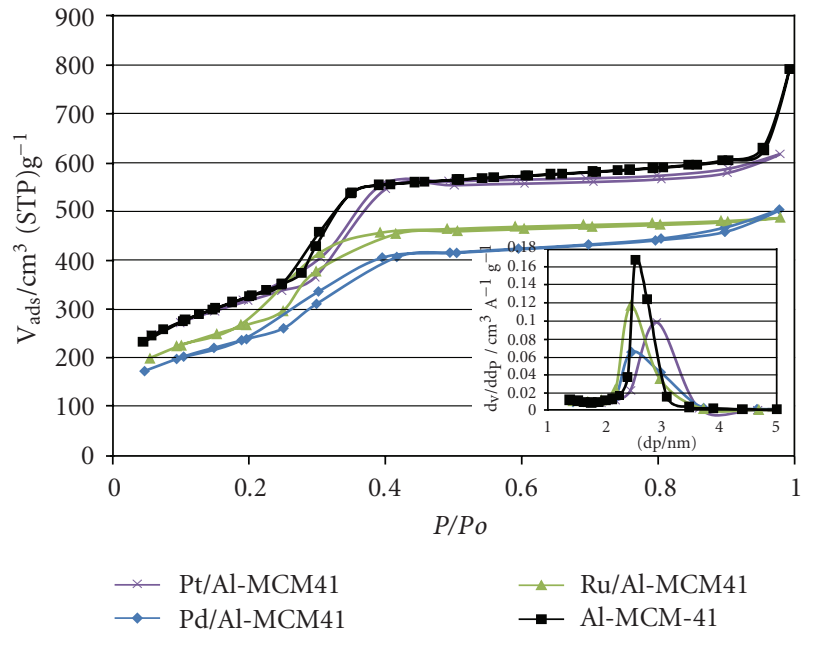

FIGURE 2: Nitrogen adsorption Isotherms at $77 \mathrm{~K}$ for M/Al-MCM41 samples.

sample $(14 \mathrm{~nm})$. The results showed above suggest that most metallic particles are supported outside of the Al-MCM-41 pores because of the calculated $d$ spacing is smaller than metallic particle size derived from Scherrer equation.

3.2. Textural Properties. Type IV $\mathrm{N}_{2}$ adsorption-desorption isotherms from all M/Al-MCM-41 materials were obtained. These isotherms are associated with capillary condensation in mesopores, which are represented by a steep slope at higher pressures. Type IV isotherms associated with mesoporosity usually exhibit hysteresis between adsorption and desorption isotherms [36]. In agreement with the IUPAC classification, M/Al-MCM-41 materials showed a small hysteresis loop type $\mathrm{H} 1$ commonly attributed to cylindrical pores (Figure 2) [37]. The pore-size distribution (PSD) determined by using a $\mathrm{BJH}$ analysis showed a narrow PSD between $2.5 \mathrm{~nm}$ to $2.7 \mathrm{~nm}$. Since PSD from Al-MCM41 was at $2.5 \mathrm{~nm}$ and M/Al-MCM-41 samples were between $2.6 \mathrm{~nm}$ and $2.7 \mathrm{~nm}$, it is possible to conclude that the pore size of M/Al-MCM-41 materials was slightly affected by metal incorporation during the synthesis.

Table 1 also shows the BET surface areas obtained from M/Al-MCM-41 materials. High surface areas were even maintained with the metal incorporation $\left(1131 \mathrm{~m}^{2} / \mathrm{g}\right.$ for Pt/Al-MCM-41 compared to $1272 \mathrm{~m}^{2} / \mathrm{g}$ for Al-MCM41). Surface area of M/Al-MCM-41 materials decreased between $11 \%-30 \%$ respects to Al-MCM-41 when metallic particles was incorporated. Surface area decrement also shows the influence of the metallic particles on the Al-MCM41 pore. The agreement between surface area and XRD results indicate that the mesoporous structure was preserved even after metal incorporation. Textural property results indicate that mesoporous materials with cylindrical pores were synthesized in all samples [38].

3.3. Elemental Composition. Metal loading values obtained were 4.28, 3.14, and 3.40\% wt. for Pt/Al-MCM-41, $\mathrm{Ru} / \mathrm{Al}-\mathrm{MCM}-41$, and $\mathrm{Pd} / \mathrm{Al}-\mathrm{MCM}-41$ samples, respectively (Table 1). The initial loading was calculated at 5\% wt for each material, which indicates that with this synthesis method, it is possible to incorporate up to $85 \%$ of metal load calculated. Figure 3 shows FESEM images and elemental mapping distribution in each sample. All samples show homogenous dispersion of metallic nanoparticles and no metallic clusters were observed. The agreement among XRD, BET, and EDS analysis indicates that by employing this synthesis method it is possible to obtain high-quality mesoporous materials with homogeneous metal dispersion and high loading of metallic catalyst particles.

3.4. Morphology. Figure 3 shows FESEM images of metallic nanoparticles of Pt (Figure 3(a)), Ru (Figure 3(b)) and Pd (Figure 3(c)) supported on Al-MCM-41 crystals. Images were taken by employing the backscattered electrons technique. Low contrast zones correspond to metallic nanoparticles and high-contrast zones correspond to Al-MCM41 support. Pt and Pd nanoparticles were observed with similar form and size (around $10 \mathrm{~nm}$ ) and homogeneously distributed on Al-MCM-41. However, in Ru/Al-MCM41 sample is possible to observe rods and round shape particles. Metallic ruthenium nanoparticles were larger than platinum and palladium nanoparticles. A statistical analysis was carried out from several images in order to determine the metallic particle size distribution (Figure 4). Crystallite size calculated from Scherrer equation (Table 1) are in agreement with the particle size observed by FESEM. Metallic particle size found and PSD suggests that the most of the nanoparticles are supported on the external surface of the AlMCM-41 and just a smaller percentage could be inside of the Al-MCM-41 pores.

Figure 4 shows TEM images of $\mathrm{Pt}, \mathrm{Ru}$, and Pd nanoparticles deposited on Al-MCM-41 crystals. In Figure 4(a), a hexagonal Al-MCM-41 crystal is observed, platinum nanoparticles around $6 \mathrm{~nm}$ to $15 \mathrm{~nm}$ are supported outside the support pores. In addition, the crystallite size obtained by the Scherrer equation, FESEM images, and TEM images for $\mathrm{Pt}, \mathrm{Ru}$, and Pd are similar (Figures 4(a), 4(b), and 4(c) resp.). 

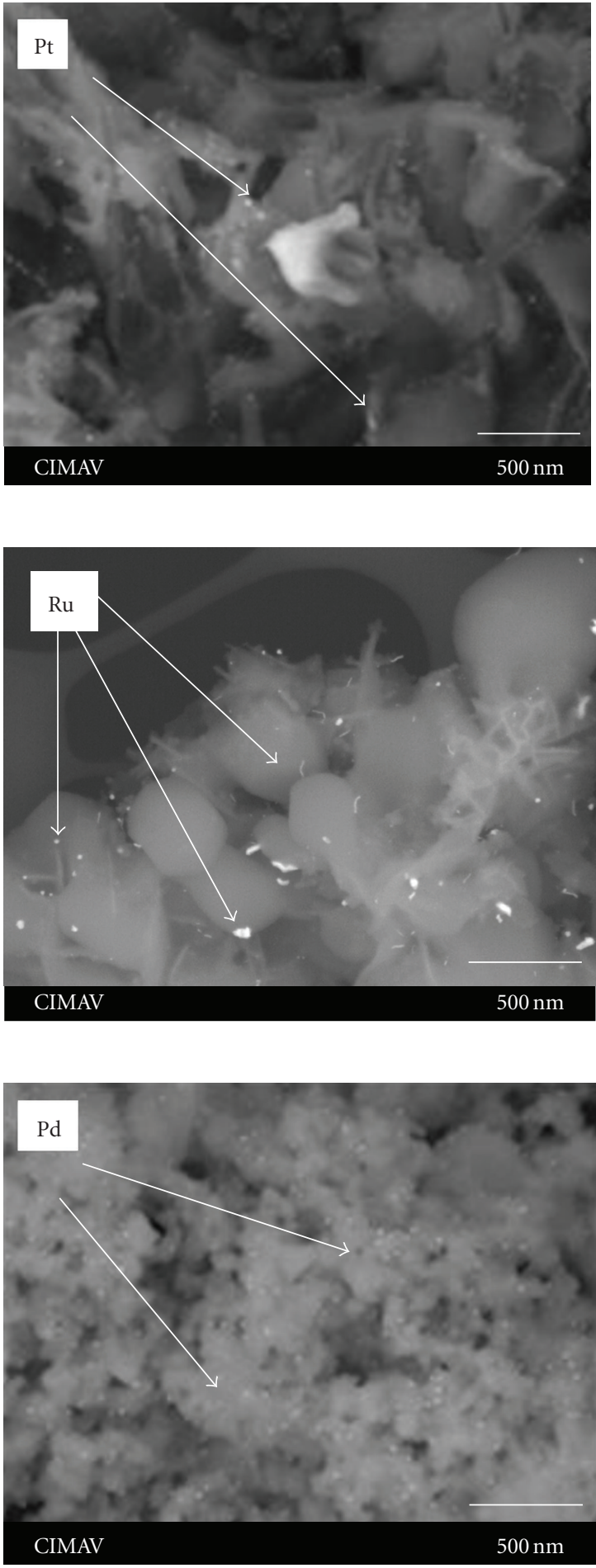
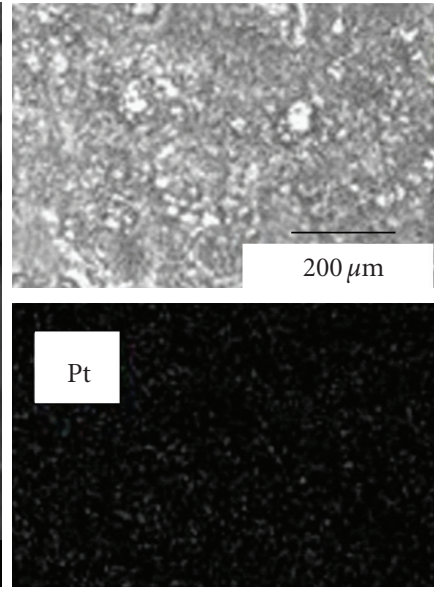

(a)
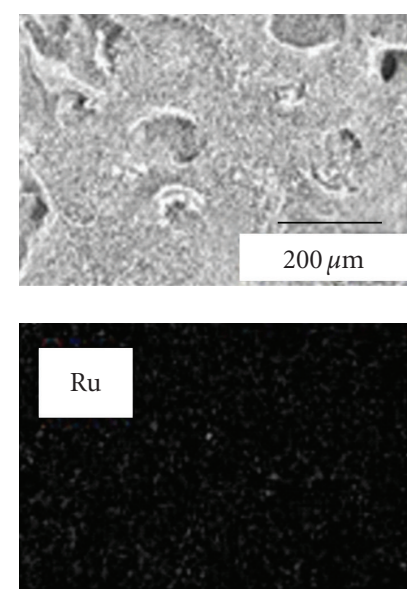

(b)
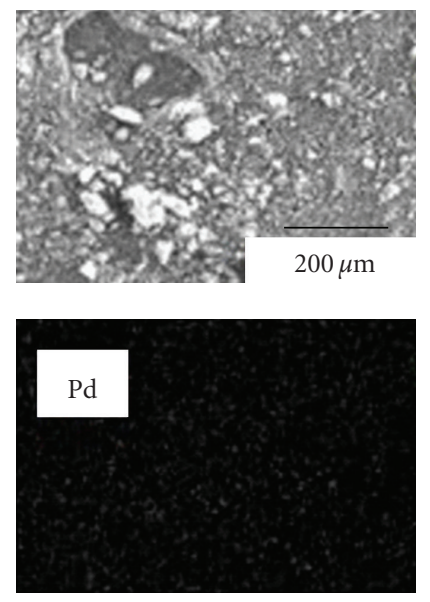

(c)
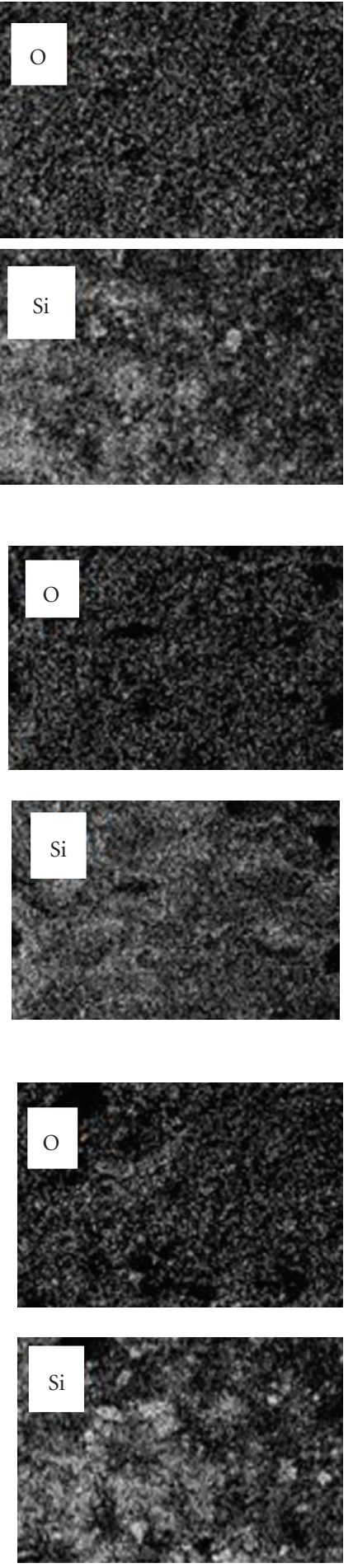

Figure 3: FESEM images of (a) Pt/Al-MCM-41, (b) Ru/Al-MCM-41, and (c) Pd/Al-MCM-41 nanoparticles and elemental mapping.

In figure 4(b), it can be observed spherical and rods particles of ruthenium supported in Al-MCM-41 crystals. Figures 4(a) and 4(c) show platinum and palladium nanoparticles on $\mathrm{Al}-$ MCM-41 crystals which have the same shape which could be associated to the nature of the metallic precursor in both samples $\left(\left(\mathrm{NH}_{4}\right)_{2} \mathrm{PtCl}_{6}\right.$ and $\left.\left(\mathrm{NH}_{4}\right)_{2} \mathrm{PdCl}_{6}\right)$. Aramendía et al. reported platinum nanoparticles with similar shape, size, and distribution supported on MSU-1 [21]. The platinum precursors used by Aramendía et al. were based in ammonium salts. On the other hand, ruthenium nanoparticles have not 


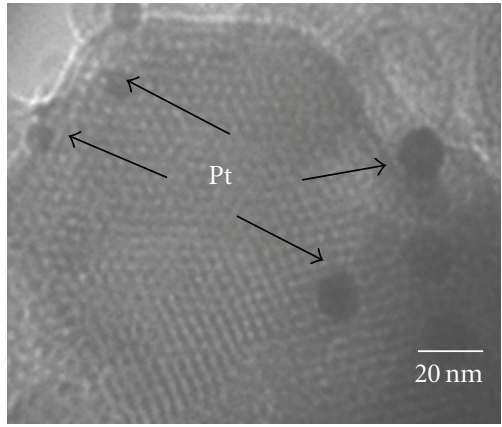

(a)

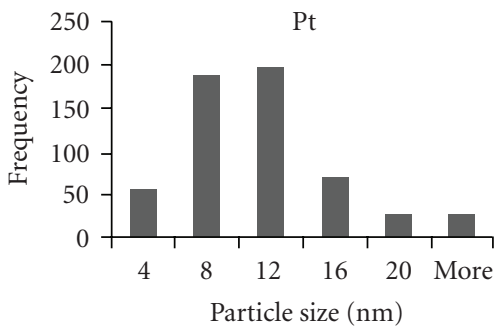

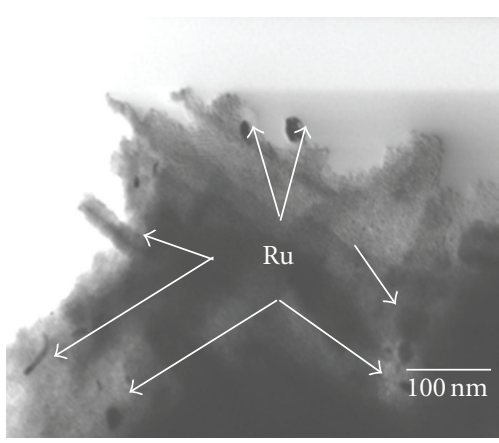

(b)

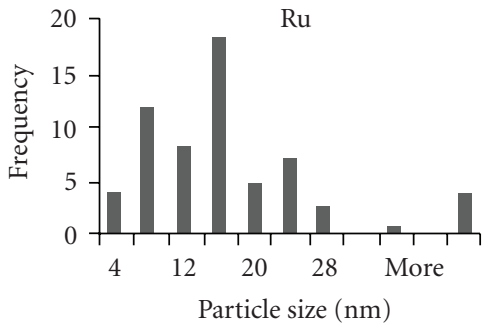

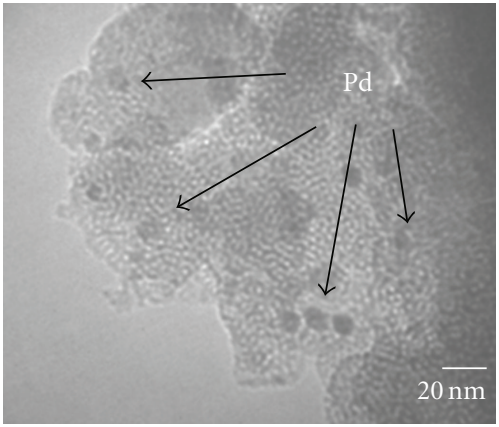

(c)

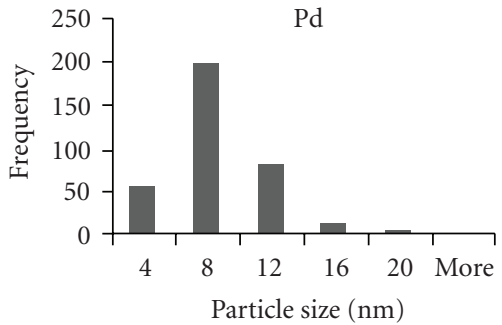

Figure 4: Transmission Electron Microscopy images. (a) Pt/Al-MCM-41, (b) Ru/Al-MCM-41, and (c) Pd/Al-MCM-41, and statistical particle size distribution of $\mathrm{Pt}, \mathrm{Ru}$, and $\mathrm{Pd}$ particles. The measures in $\mathrm{Ru}$ case were taken from the width of the rod and the diameter of the round particles.

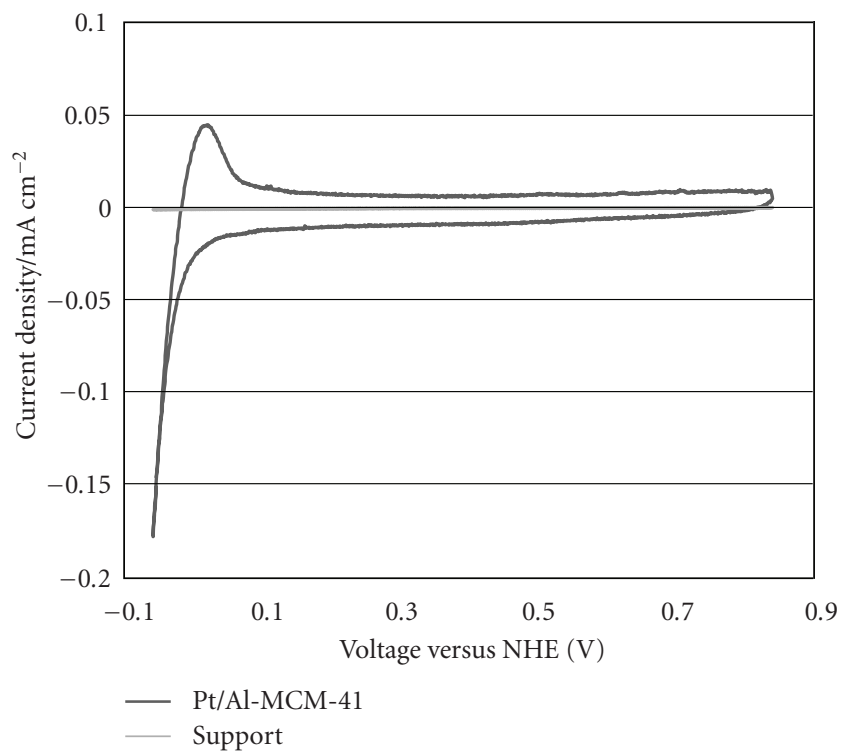

Figure 5: Cyclic Voltammograms of Pt/Al-MCM-41 and Al-MCM41 in $1 \mathrm{M} \mathrm{H}_{2} \mathrm{SO}_{4}$. Scan initiated at $-0.060 \mathrm{~V}$ versus $\mathrm{NHE}$ in positive direction using $20 \mathrm{mV} / \mathrm{s}$. Working electrode area $=0.07 \mathrm{~cm}^{2}$.

only round shape particles but also rods form; the difference could be attributed to nature of the metallic precursor used in this case $\left(\mathrm{RuCl}_{3}\right)$. This difference affects the shape and size of ruthenium particles even though the same synthesis method is used. In all samples, metallic nanoparticles were observed blocking some Al-MCM-41 pores, hereby surface area decreases when metals are incorporated to Al-MCM- 41 .
3.5. Cyclic Voltammetry Analysis. Cyclic Voltammetry (CV) curve in Figure 5 shows Pt/Al-MCM-41 sample and support without platinum for comparison. A peak associated with hydrogen oxidation appears only for Pt/Al-MCM-41 sample near to $0 \mathrm{~V}$ versus normal hydrogen electrode (NHE). CV technique was employed to obtain the electrochemical active area (EAA) from hydrogen oxidation peak using the charge associated with hydrogen-adatoms desorption $\left(Q_{H}\right)$ in

$$
\mathrm{EAA}=\frac{Q_{\mathrm{H}}}{\left(Q_{\mathrm{Ho}} G_{\mathrm{Me}}\right)},
$$

where $Q_{\text {но }}$ is the charge required for oxidation of a single molecule of $\mathrm{H}_{2}$ on a polycrystalline Pt surface of $1 \mathrm{~cm}^{2}$ $\left(210 \mathrm{mC} / \mathrm{cm}^{2}\right)[39,40] . G_{\mathrm{Me}}$ is the metal loading in the working electrode.

The EAA obtained from Pt/Al-MCM-41 was $4.46 \mathrm{~m}^{2} / \mathrm{g}$ which suggest that hydrogen oxidation occurred in the proposed material. This type of electrocatalytic activity shows that Pt/Al-MCM41 can be use as electrode in electrochemical devices, however, more extensive studied is needed

\section{Conclusions}

$\mathrm{Pt}, \mathrm{Ru}$, and $\mathrm{Pd}$ incorporation in $\mathrm{Al}-\mathrm{MCM}-41$ was carried out by direct synthesis. M/Al-MCM-41 showed high-surface areas (up to $1131 \mathrm{~m}^{2} / \mathrm{g}$ ) and the PSD suggests that materials have unidirectional cylindrical pores with diameter between $2.5 \mathrm{~nm}$ to $3 \mathrm{~nm}$. Metallic particle size achieved was 8,14 , and $6 \mathrm{~nm}$ for $\mathrm{Pt}, \mathrm{Ru}$, and $\mathrm{Pd}$, respectively. Metallic precursor nature affected the metallic nanoparticles form. Elemental analyses show high metal nanoparticle loadings (up to $85 \%$ of yield). Metal particles were homogeneously dispersed on 
the Al-MCM-41 crystals. Finally, electrochemical response shows a hydrogen oxidation peak when $\mathrm{Pt}$ is incorporated to the Al-MCM-41 sample, therefore Pt/Al-MCM-41 could considered as electrocatalysts in some electrochemical applications.

\section{Acknowledgments}

The authors thank CONACYT Project 26067 and they would like to be grateful for the valuable technical assistance from D. Lardizabal and Luis de la Torre.

\section{References}

[1] L. Li, P. Wu, Q. Yu, G. Wu, and N. Guan, "Low temperature $\mathrm{H}_{2}$-SCR over platinum catalysts supported on Ti-containing MCM-41," Applied Catalysis B, vol. 94, no. 3-4, pp. 254-262, 2010.

[2] Y. Xie, K. K. Sharma, A. Anan, G. Wang, A. V. Biradar, and T. Asefa, "Efficient solid-base catalysts for aldol reaction by optimizing the density and type of organoamine groups on nanoporous silica," Journal of Catalysis, vol. 265, no. 2, pp. 131-140, 2009.

[3] J. A. Wang, L. F. Chen, L. E. Noreña, and J. Navarrete, "Spectroscopic study and catalytic evaluation of mesostructured AlMCM-41 and Pt/ $\mathrm{H}_{3} \mathrm{PW}_{12} \mathrm{O}_{40} / \mathrm{Al}-\mathrm{MCM}-41$ catalysts," Applied Catalysis A, vol. 357, no. 2, pp. 223-235, 2009.

[4] A. Taguchi and F. Schüth, "Ordered mesoporous materials in catalysis," Microporous and Mesoporous Materials, vol. 77, no. 1, pp. 1-45, 2005.

[5] C. T. Kresge, M. E. Leonowicz, W. J. Roth, J. C. Vartuli, and J. S. Beck, "Ordered mesoporous molecular sieves synthesized by a liquid-crystal template mechanism," Nature, vol. 359, no. 6397, pp. 710-712, 1992.

[6] J. S. Beck, J. C. Vartuli, W. J. Roth et al., "A new family of mesoporous molecular sieves prepared with liquid crystal templates," Journal of the American Chemical Society, vol. 114, no. 27, pp. 10834-10843, 1992.

[7] N. Wang, Y. Shao, Z. Shi, J. Zhang, and H. Li, "Influence of MCM-41 particle on mechanical and morphological behavior of polypropylene," Materials Science and Engineering A, vol. 497, no. 1-2, pp. 363-368, 2008.

[8] N. Sudheesh, S. K. Sharma, R. S. Shukla, and R. V. Jasra, "HRh $(\mathrm{CO})\left(\mathrm{PPh}_{3}\right)_{3}$ encapsulated mesopores of hexagonal mesoporous silica (HMS) acting as nanophase reactors for effective catalytic hydroformylation of olefins," Journal of Molecular Catalysis A, vol. 296, no. 1-2, pp. 61-70, 2008.

[9] J. Feng, S.-Y. Song, W.-Q. Fan et al., "Near-infrared luminescent mesoporous MCM-41 materials covalently bonded with ternary thulium complexes," Microporous and Mesoporous Materials, vol. 117, no. 1-2, pp. 278-284, 2009.

[10] S. D. Alvarez, A. M. Derfus, M. P. Schwartz, S. N. Bhatia, and M. J. Sailor, "The compatibility of hepatocytes with chemically modified porous silicon with reference to in vitro biosensors," Biomaterials, vol. 30, no. 1, pp. 26-34, 2009.

[11] M. Popova, Á. Szegedi, P. Németh, N. Kostova, and T. Tsoncheva, "Titanium modified MCM-41 as a catalyst for toluene oxidation," Catalysis Communications, vol. 10, no. 3, pp. 304-308, 2008.

[12] E. Fois, A. Gamba, and G. Tabacchi, "Influence of silanols condensation on surface properties of micelle-templated silicas: a modelling study," Microporous and Mesoporous Materials, vol. 116, no. 1-3, pp. 718-722, 2008.
[13] M. Ghiaci, H. Aghaei, S. Soleimanian, and M. E. Sedaghat, "Enzyme immobilization. Part 1. Modified bentonite as a new and efficient support for immobilization of Candida rugosa lipase," Applied Clay Science, vol. 43, no. 3-4, pp. 289-295, 2009.

[14] F. Adam and A. Iqbal, "The oxidation of styrene by chromiumsilica heterogeneous catalyst prepared from rice husk," Chemical Engineering Journal, vol. 160, no. 2, pp. 742-750, 2010.

[15] S. Chaliha and K. G. Bhattacharyya, "Fe(III)-, Co(II)- and $\mathrm{Ni}(\mathrm{II})$-impregnated MCM41 for wet oxidative destruction of 2,4-dichlorophenol in water," Catalysis Today, vol. 141, no. 12, pp. 225-233, 2009.

[16] E. I. Gil'debrand, International Journal of Chemical Engineering, vol. 6, pp. 449-480, 1966.

[17] W. M. H. Sachtler and Z. Zhang, "Zeolite supported transition metal catalysts," Advanced Synthesis \& Catalysis, vol. 39, p. 129, 1993.

[18] G. Jacobs, C. L. Padro, and D. E. Resasco, "Comparative study of n-hexane aromatization on $\mathrm{Pt} / \mathrm{KL}, \mathrm{Pt} / \mathrm{Mg}(\mathrm{Al}) \mathrm{O}$, and $\mathrm{Pt} / \mathrm{SiO}_{2}$ catalysts: clean and sulfur-containing feeds," Journal of Catalysis, vol. 179, no. 1, pp. 43-55, 1998.

[19] N. Yao, C. Pinckney, S. Lim, C. Pak, and G. L. Haller, "Synthesis and characterization of Pt/MCM-41 catalysts," Microporous and Mesoporous Materials, vol. 44-45, pp. 377$384,2001$.

[20] U. Junges, W. Jacobs, I. Voigt-Martin, B. Krutzsch, and F. Schüth, "MCM-41 as a support for small platinum particles: a catalyst for low-temperature carbon monoxide oxidation," Journal of the Chemical Society, Chemical Communications, no. 22, pp. 2283-2284, 1995.

[21] M. Á. Aramendía, V. Borau, C. Jiménez, J. M. Marinas, and F. J. Romero, "Supramolecular templated synthesis of platinumsupported silica," Chemical Communications, no. 10, pp. 873874, 1999.

[22] H. Wakayama, N. Setoyama, and Y. Fukushima, "Sizecontrolled synthesis and catalytic performance of Pt nanoparticles in micro- and mesoporous silica prepared using supercritical solvents," Advanced Materials, vol. 15, no. 9, pp. 742$745,2003$.

[23] P. L. Dhepe, A. Fukuoka, and M. Ichikawa, "Preparation of highly dispersed RhPt alloy catalysts in mesoporous silica using supercritical carbon dioxide and selective synthesis of ethane in butane hydrogenolysis," Chemical Communications, vol. 9, no. 5, pp. 590-591, 2003.

[24] T. Yamamoto, T. Shido, S. Inagaki, Y. Fukushima, and M. Ichikawa, "Ship-in-bottle synthesis of $\left[\mathrm{Pt}_{15}(\mathrm{CO})_{30}\right]^{2}$ - encapsulated in ordered hexagonal mesoporous channels of FSM-16 and their effective catalysis in water-gas shift reaction," Journal of the American Chemical Society, vol. 118, no. 24, pp. 58105811, 1996.

[25] T. Yamamoto, T. Shido, S. Inagaki, Y. Fukushima, and M. Ichikawa, "A robust platinum carbonyl cluster anion $\left[\mathrm{Pt}_{3}(\mathrm{CO})_{6}\right]^{52}$ - encapsulated in an ordered mesoporous channel of FSM-16: FTIR/EXAFS/TEM characterization and catalytic performance in the hydrogenation of ethene and 1,3butadiene," Journal of Physical Chemistry B, vol. 102, no. 20, pp. 3866-3875, 1998.

[26] W. Zhou, J. M. Thomas, D. S. Shephard et al., "Ordering of ruthenium cluster carbonyls in mesoporous silica," Science, vol. 280, no. 5364, pp. 705-708, 1998.

[27] R. Raja, T. Khimyak, J. M. Thomas, S. Hermans, and B. F. G. Johnson, "Single-step, highly active, and highly selective 
nanoparticle catalysts for the hydrogenation of key organic compounds," Angewandte Chemie, vol. 40, no. 24, pp. 46384642, 2001.

[28] D. S. Shephard, T. Maschmeyer, G. Sankar et al., "Preparation, characterisation and performance of encapsulated copperruthenium bimetallic catalysts derived from molecular cluster carbonyl precursors," Chemistry, vol. 4, no. 7, pp. 1214-1224, 1998.

[29] J. Garcia-Martinez, N. Linares, S. Sinibaldi, E. Coronado, and A. Ribera, "Incorporation of Pd nanoparticles in mesostructured silica," Microporous and Mesoporous Materials, vol. 117, no. 1-2, pp. 170-177, 2009.

[30] C. Schüth, S. Disser, F. Schüth, and M. Reinhard, "Tailoring catalysts for hydrodechlorinating chlorinated hydrocarbon contaminants in groundwater," Applied Catalysis B, vol. 28, no. 3-4, pp. 147-152, 2000.

[31] C. P. Mehnert and J. Y. Ying, "Palladium-grafted mesoporous MCM-41 material as heterogeneous catalyst for Heck reactions," Chemical Communications, no. 22, pp. 2215-2216, 1997.

[32] C. P. Mehnert, D. W. Weaver, and J. Y. Ying, "Heterogeneous heck catalysis with palladium-grafted molecular sieves," Journal of the American Chemical Society, vol. 120, no. 47, pp. 12289-12296, 1998.

[33] M. M. L. Ribeiro Carrott, F. L. Conceição, J. M. Lopes et al., "Comparative study of Al-MCM materials prepared at room temperature with different aluminium sources and by some hydrothermal methods," Microporous and Mesoporous Materials, vol. 92, no. 1-3, pp. 270-285, 2006.

[34] L. Wang, T. Qi, Y. Zhang, and J. Chu, "Morphosynthesis route to large-pore SBA-15 microspheres," Microporous and Mesoporous Materials, vol. 91, no. 1-3, pp. 156-160, 2006.

[35] Q. Huo, D. I. Margolese, and G. D. Stucky, "Surfactant control of phases in the synthesis of mesoporous silica-based materials," Chemistry of Materials, vol. 8, no. 5, pp. 1147-1160, 1996.

[36] S. Brunauer, L. S. Deming, W. E. Deming, and E. Teller, "On a theory of the van der Waals adsorption of gases," Journal of the American Chemical Society, vol. 62, no. 7, pp. 1723-1732, 1940.

[37] K. S. W. Sing, D. H. Everett, R. A. W. Haul, et al., "Reporting physisorption data for gas/solid systems with special reference to the determination of surface area and porosity," Pure and Applied Chemistry, vol. 57, no. 4, pp. 603-619, 1985.

[38] "Development of a formation mechanism for M41S," in Zeolites and Related Microporous Materials: State of Art, J. Weitkamp, H. G. Karge, H. Pfeifer, and W. Holderich, Eds., pp. 53-60, Elsevier Science B.V., Amsterdam, The Netherlands, 1994.

[39] M. R. Tarasevich, V. A. Bogdanovskaya, B. M. Grafov et al., "Electrocatalytic properties of binary systems based on platinum and palladium in the reaction of oxidation of hydrogen poisoned by carbon monoxide," Russian Journal of Electrochemistry, vol. 41, no. 7, pp. 746-757, 2005.

[40] B.B. Damaskin and O. A. Petrii, Introduction to Electrochemical Kinetics, Vysshaya Shkola, Moscow, Russia, 1975. 

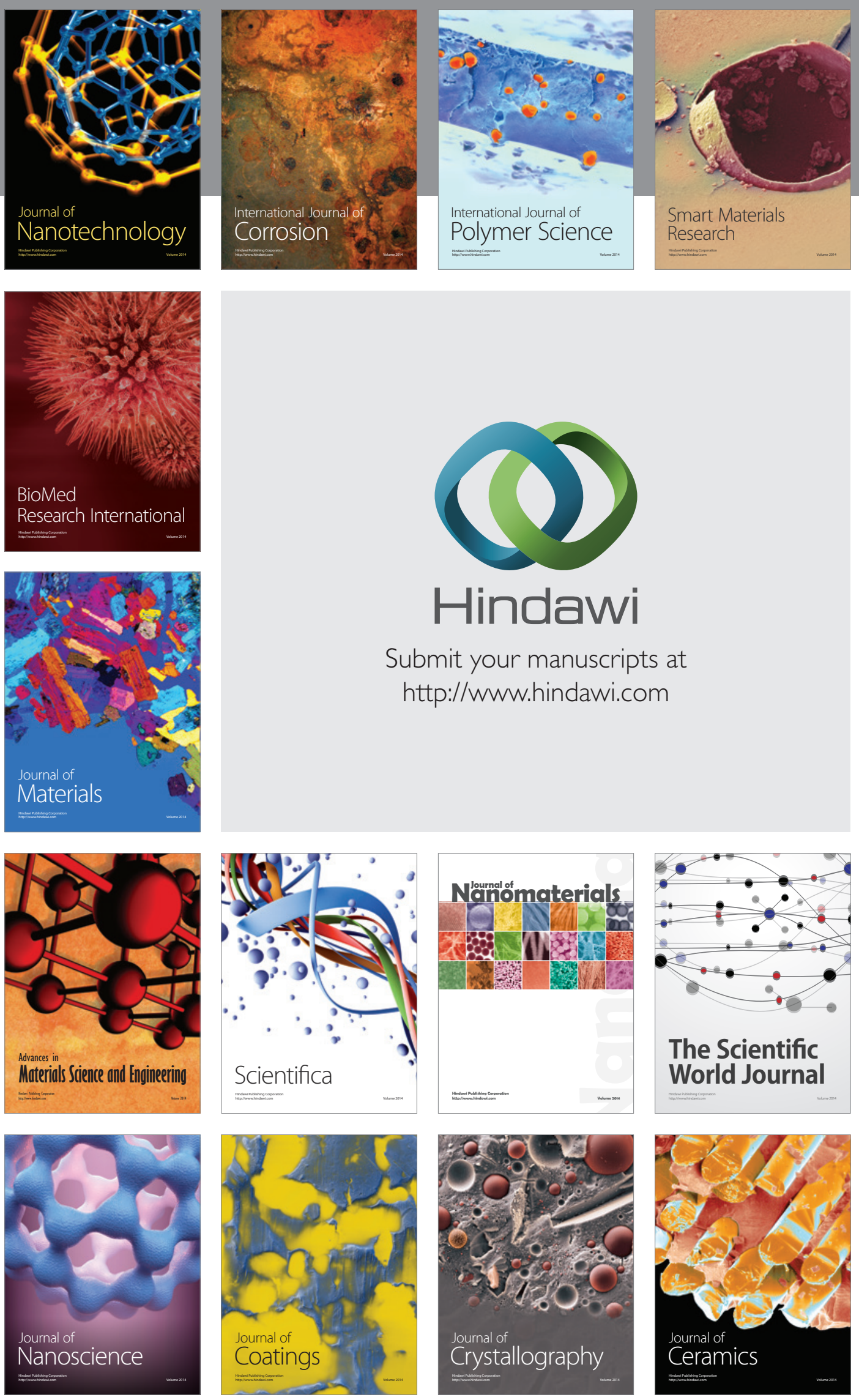

The Scientific World Journal

Submit your manuscripts at

http://www.hindawi.com

\section{World Journal}

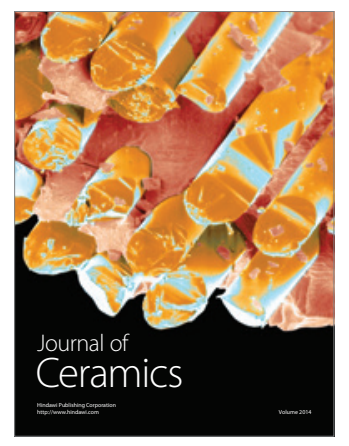

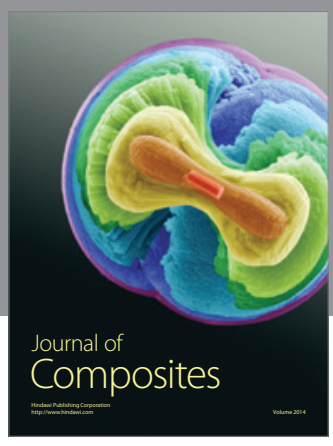
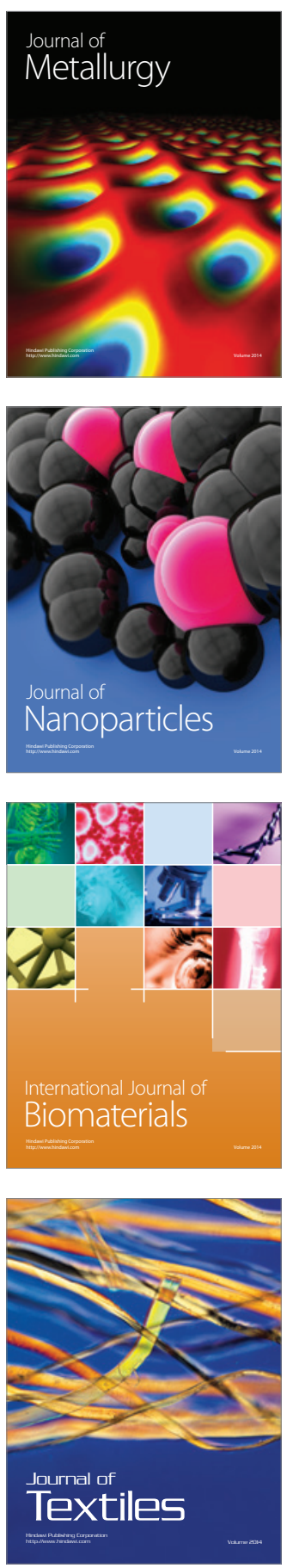